\title{
La frontera no deja ver la montaña: invisibilización de la cordillera de Los Andes en la Norpatagonia chileno-argentina ${ }^{1}$
}

\author{
Andrés Núñez ${ }^{2}$
}

\begin{abstract}
RESUMEN
El presente artículo se refiere a la relación entre frontera y montaña. En una mirada geohistórica se plantea analizar el proceso a través del cual la cordillera de Los Andes perdió presencia cultural para superponerse como frontera política. Ello ha Ilevado a que hasta la actualidad, la montaña y la cordillera de Los Andes en Chile haya sido dominada por una lectura que la homologa con la idea de barrera, línea o "raya". Desde esta perspectiva, la cordillera se interpreta como un espacio físico que sirve para separar a "unos" de "otros". Aquello ha invisibilizado o minimizado el valor sociocultural que la cordillera de Los Andes ha tenido históricamente y que posee en el presente. Analizamos el caso de la Norpatagonia chileno-argentina para mostrar el histórico enclave que ella representó y proyectó, el que fue resignificado a partir de la presencia de una frontera jurídica.
\end{abstract}

Palabras clave: Frontera, Montaña, Norpatagonia, Región, Representación.

\begin{abstract}
This article concerns the relationship between border and mountain. At a geohistoric perspective we analyzed the process through which the Andes lost cultural presence as a political boundary overlap. This has led to the present, the mountains and the Andes in Chile has been dominated by a reading that homologous with the idea of barrier or "line". From this perspective, the Anes is interpreted as a physical space serves to separate the "ones" of "other". That has obscured or minimized the socio-cultural value to the Andes has had historically and which has at present. Analyze the case of the Chilean North Patagonia-Argentina to show the historical enclave she meant and planned, which was re-meaning from the presence of a legal border.
\end{abstract}

Key words: Border, Mountain, North-Patagonia, Region, Representation.

1 Proyecto Posdoctoral CONICYT No 3110027 Estudio de la frontera norpatagónica chilena y argentina: de la línea divisoria a la frontera permeable o intercultural. Siglos XIX y XX. Artículo recibido el 22 de mayo de 2012, aceptado el 15 septiembre de 2012 y corregido el 29 de marzo de 2013.

2 Instituto de Geografía, Pontificia Universidad Católica de Chile (Chile). E-mail: aanunezg@uc.cl 
En la actualidad en Chile la cordillera de Los Andes conserva la imagen de una barrera, línea o raya cuya omnipresencia natural sirve para separar dos naciones, la chilena y la argentina. La escala de esta representación, como puede verse, es de nivel nacional. Aquella "fuerza natural", tan familiar y evidente a nuestros ojos, sin embargo, no siempre reflejó aquella posición. En forma previa, su representación y modo de comprender la cordillera se vinculó a una serie de intercambios, conflictos, circulaciones o vínculos de un lado y otro que la proyectó más que como barrera como área de soporte de aquellas relaciones sociales y culturales. De este modo, se observa un proceso, impulsado por los Estados nacionales durante el siglo XIX y muy concerniente con el tiempo de la racionalización territorial llevada a cabo por ellos, que colaboró a que la imagen de la cordillera adquiriese (y requiriese) una nueva lectura, un nuevo horizonte interpretativo: un macizo nevado de gran elevación, impenetrable y desértico ${ }^{3}$. Aquella resignificación de la cordillera iba de la mano a la necesidad de fijar una frontera política que delineara de forma clara a la nación chilena en relación a la argentina.

De esta suerte, el dominio discursivo de la cordillera como sinónimo de frontera o límite colaboró a que ella, la cordillera, la montaña, perdiese otras lecturas, otros saberes, como por ejemplo los asociados a una cordillera social y cultural. Es decir, la cordillera física se impuso, en la escala nacional, a la cordiIlera cultural. En otras palabras, la cordillera de Los Andes fue jerarquizada como frontera política y natural entre dos países, ocultando o encubriendo saberes locales o referencias específicas que hacían de ella un espacio de

3 La imagen del desierto implica un espacio vacío, deshumanizado. Usamos el término en el mismo sentido dado por numerosos investigadores argentinos respecto de la Campaña del Desierto en la conquista de territorios patagónicos hacia fines del siglo XIX y la construcción de los Territorios Nacionales. Al respecto, puede consultarse los trabajos de Pedro Navarro Floria $(1999,2002,2007)$ y Carla Lois (1999, 2004). Del lado argentino, nos advierte el propio Navarro Floria, la cordillera y la zona andina de la Norpatagonia fueron en una primera instancia desierto y luego una tierra fértil que se asoció y resumió en la imagen de la Suiza argentina" (2007: 38-39) sociabilidad más que de barrera o muralla. Como era un asunto de Estado, aquella necesidad de "elevar" la cordillera, cual contrafuerte, se llevó a cabo como estrategia de poder ante la necesidad de delinear una soberanía territorial. Los tiempos y los procesos de este cambio en los diferentes espacios de montaña no fueron sin duda similares. Pero la racionalidad territorial de la escala nacional, actuando con perspectiva universal y con un marcado énfasis ideológico, llevó a velar otros sentidos que la cordillera tuvo $-y$ sin duda los tiene aún- en una dimensión menor, local o regional.

Desde este punto de vista, el presente texto apunta a ponderar los niveles o escalas de análisis territorial y de poder. Es decir, colabora a comprender que los territorios presentan lecturas diversas, plurales que no necesariamente se condicen con interpretaciones de carácter central o de nivel nacional como tampoco de orden normativo y abstracto, aunque estas muchas veces influyan sobre aquellas. En la actualidad, asimilaciones territoriales asumidas bajo la ideología de la globalización imponen una situación escalar similar a la acaecida en el siglo XIX desde un Estado nacional que racionalizó el territorio bajo un imaginario de poder surgido desde el centro y en base a valores y proyecciones que, muchas veces, poco o nada tenía que ver con lo que sucedía a nivel o escala "regional". Es decir, produjo un espacio politizado para lo cual organizó el territorio bajo un prisma impositivo, lo que desvalorizó o invisibilizó una producción espacial de escala menor (Núñez, 2009) .

Nos parece que un buen ejemplo de aquello se da en el proceso de construcción de una frontera política que llevó a anular o

\footnotetext{
4 Grimson (2000b) plantea que la construcción de una región o zona fronteriza no es solo la imposición de arriba hacia abajo o desde el centro hacia la periferia, ya que los procesos de territorialización implican una dialéctica y grados de retroalimentación entre las partes. En efecto, acá se constata que determinadas producciones sociales son minimizadas o invisibilizadas en nombre de estructuras ideológicas de alcance más amplio "la patria", "la historia nacional", "la montaña es una frontera", etc.) y que en base a la consolidación de esas producciones los sujetos sociales se resignifican.
} 
velar la referencialidad que actores sociales regionales o locales poseían y poseen de la cordillera de Los Andes. El resultado: la frontera se impone a la montaña.

Para exponer el asunto, dividiremos el texto en cuatro partes. La primera está orientada a otorgar un marco teórico al problema, es decir, a trabajar en torno a la historicidad del espacio, y por ende de la montaña, llevando a observar que la relación entre espacio geográfico y montaña no es un asunto únicamente físico. Un segundo punto, siguiendo la línea anterior, se concentra en analizar diversos usos e interpretaciones de la montaña, buscando con ello relativizar la idea dominante de montaña como sinónimo de frontera. Un tercer título, Ilamado "Fronteras políticas, fronteras diseñadas", tiene por propósito mostrar el contexto histórico en que la montaña se alza como una fuerza divisoria. Finalmente, nos centramos en la escala regional, la Norpatagonia andina chileno-argentina, a fin de indicar que su territorialidad ha sido dinámica, móvil y cambiante y, en este contexto, durante largos períodos ha sido concebida como una región en sí misma, incluyendo la cordillera de Los Andes que, desde una perspectiva únicamente política, solo sería útil a los propósitos de separar la región en dos espacialidades diferentes.

\section{Historicidad del espacio: definiendo la cordillera de Los Andes}

De acuerdo a la Real Academia Española y a otros diccionarios consultados, el término cordillera es "una serie de montañas enlazadas entre sí". Si observamos la palabra montaña, ella se define como una "elevación natural del terreno de gran altura, que destaca del entorno; tiene mayor altitud que una colina y un volumen superior al del monte". A su vez, asocia el término frontera al "confín de un Estado", significando con ello que se trata de una "raya que divide las poblaciones, provincias, territorios, etc., y señala los límites de cada uno". En ambos casos, uno se remite solo al aspecto físico de la cordillera y montaña y en el otro se define únicamente a partir de un límite en el marco del surgimiento de los Estados-nación. Sin embargo, nada expresan sobre otras perspectivas, desde un contexto temporal o hermenéutico, de lo que podría entenderse por cordillera, montaña o frontera.

En este sentido, es relevante, a fin de ampliar la mirada, tener a la vista los planteamientos del sociólogo francés Bourdieu (1988: 115) respecto si es posible trabajar e interpretar determinadas nociones o tipo de lenguaje social sin preguntarse sobre qué y cómo se definen, cómo se estructuran. Es decir, si es factible trabajar sobre la relación montaña-frontera sin intentar comprender el horizonte cultural o histórico que lo ha proyectado y los proyectan en el presente. Este asunto es vital, por cuanto la imagen de frontera comúnmente aceptada, es decir, una línea, surge en un marco temporal específico e influido por determinada escala territorial, nacional en este caso. Este imaginario cultural de la frontera, surgido al alero de la configuración del Estado-nación, ha colaborado a modelar o fijar un sentido de la montaña -el de barrera- que no siempre ha encajado con representaciones territoriales cuya historicidad es más específica o se ha movido a otra escala, regional, por ejemplo.

La interpretación dominante de frontera como sinónimo de línea es una consolidación tardía, que se puede fijar hacia fines del siglo XIX y principios del XX con la maduración de los Estados-nación y supone territorios y sociedades distintas de un lado y otro, aunque cada una de estas, en su fuero interno, homogéneas. Sin embargo, como veremos, la frontera no necesariamente ha separado una cosa de otra, ya que ha sido también un lugar común, un espacio integrado en sí mismo, con sus códigos, sus representaciones, sus conflictos, que no se condicen necesaria o únicamente con la "línea de la nación". Es decir, una frontera fue y puede ser comprendida también como "región".

Interesa, entonces, exponer que la territorialidad de la montaña en Chile, es decir su proceso de significación territorial, y con ello la cordillera de Los Andes, se ha ido forjando mediada o dominada por un lenguaje cultural que aún se encuentra fuertemente arraigado en torno al surgimiento de las fronteras como límite "natural" de la nación chilena y argentina (siglo XIX). 
Al plantear la metáfora de "la frontera no deja ver la montaña", parte del título, estamos refiriéndonos a la necesidad de comprender la montaña y la frontera desde una historicidad múltiple y diversa, menos monopólica. Esta actitud unívoca se ha asociado al modo de objetivización a través del cual lo que comprendemos por frontera y montaña se transforma en discurso dominante 0 , como lo ha Ilamado Foucault, verdadero ${ }^{5}$. Así, la transmisión histórica a partir de la cual visualizamos y le damos un sentido a la montaña, es en sí un acto lingüístico-sociocultural, que está "cargado" de efectos. La comprensión de la montaña, desde este planteamiento, no es un asunto que nos llegue de manera "vacía" u objetiva (Gadamer, 1999). Por el contrario, su percepción está intervenida por aquella interpretación de carácter histórico que proyectada al futuro la fija como un lugar predominantemente natural que sirve para dividir o separar una nación de otra. Su noción se legitima en un uso y discurso dominante, de poder, minimizando otras interpretaciones respecto de su territorialidad ${ }^{6}$.

El espacio geográfico es, desde esta lógica, a la vez que materia, historicidad. De este modo, dado que el hombre se desenvuelve en el mundo, en el Dasein, las actitudes, los valores asociados a determinados espacios geográficos, la montaña por ejemplo, irán mutando a través del tiempo, por lo que lo que significó un espacio geográfico para unos no será lo mismo para otros, transformándose un mismo espacio en ilegible a partir del tiempo.

Aquella historicidad de la cordillera de Los Andes arraigada en un vínculo político ha colaborado, por tanto, a invisibilizar numerosas otras perspectivas. La montaña, en escala

5 “... el estudio de los modos según los cuales el sujeto ha podido ser insertado como objeto en los juegos de verdad, a través de qué formas diversas y particulares de gobierno de los individuos" (Foucault, 1999: III, 16).

6 Fija Gadamer (1999), a través de una Hermenéutica Ontológica, que el que comprende siempre lo hace en un contexto histórico, que es, a su vez, una creación interpretativa, cuyos efectos se desenvuelven y proyectan en el presente. Así, la interpretación histórica no es el pasado sino su secuela, un resultado que no es fijado para siempre -en el pasado- sino que es móvil y cambiante de acuerdo a nuevos procesos interpretativos. amplia, ha manifestado variados significados, desde religiosos hasta una barrera inexpugnable. Ella, por ende, como espacio geográfico tangible, es parte de una "producción de sentidos y valores" (Geertz, 1987: 24-25).

Durante el siglo XIX y principios del XX, la cordillera de Los Andes fue transformándose en un medio necesario para constituir frontera $y$, de ese modo, construir la nación. Es decir, la naturalizó. El naciente Estadonación dibujó sus límites, delineando un territorio propio, marcando con ello en la cordillera de Los Andes el nicho ideal o "natural", como dijimos, para diferenciarse de los otros. El antropólogo argentino Diego Escolar lo ilustra de forma muy clara para el caso argentino al expresar: "... la instalación de la imagen de la frontera natural andina fue un poderoso efecto de verdad con concretos efectos geopolíticos y sociales en el proceso -articulado desde la segunda mitad del siglo XIX- de sustancialización espacial del Estado nacional argentino. Hasta hoy, la consecuencia más notoria fue la relativa invisibilización de la cordillera de Los Andes como área de producción, sociabilidad e intercambio y, especialmente, de los actores sociales que participan en esta dinámica, pese a que grupos locales provenientes en su mayoría del sector chileno continuaron desplazándose estacionalmente a los valles interandinos manteniendo vínculos sociales, económicos y culturales transcordilleranos" (2000: 260).

Ahora bien, la historicidad de la cordillera no es, como manifestamos, su pasado sino su proyección, por lo que la humanización de Los Andes, bajo el proceso de creación de los nacionalismos, es decir, la idealización a imagen del hombre, configuró un sentido dominante para ella que opacó o anuló otros, cual historia oficial: "la montaña es una frontera", es decir, una "raya". Aquello no implica que ella presente una "lectura oculta" o "no descubierta", ya que lo que despliega, simplemente, son otros significados, para otros hombres. Esos valores, esas visiones de mundo están allí, lo que sucede es que no se han legitimado o expandido como conocimiento de poder.

En este contexto, una definición de cordillera de Los Andes que la homologa con una frontera política resulta excluyente de 
una serie de dinámicas territoriales en torno a ella que precisamente resaltan un sentido relacional y referencial tanto de la montaña como de los espacios fronterizos. Como será expuesto más adelante, la región andina de la Norpatagonia chileno-argentina es buen ejemplo de nuestro planteamiento, aunque claramente no el único.

En definitiva, en el análisis de la montaña que acá se lleva a cabo se busca intentar responder a esta pregunta: “¿cómo han aparecido tales o cuales objetos posibles de conocimiento y poder?" (Foucault, 1999: 22 ), en nuestro caso, la imagen -para el caso chileno- de una frontera que ha llevado a representar a la montaña como un área ajena, cuya función y valorización principal es la de ser el "límite de la nación"7. También, resulta importante preguntarse cómo se instalan aquellos objetos posibles de conocimiento y poder, a partir de los cuales más adelante se enumerarán una serie de estrategias que colaboraron a que ellos aparecieran y se situaran.

\section{Espacio diverso, montaña plural: valor y representación de la cordillera en los siglos XVIII y XIX}

Antes de exponer la producción de la frontera política a partir de la cordillera de Los Andes, visualizaremos aquellos otros valores y representaciones que de ella y de la montaña en general, se generan a partir de otros contextos históricos. Aquello colaborará a poner en perspectiva el problema aquí formulado.

En la antigüedad la montaña fue asociada más bien a un "espacio mágico", justificando con ello una interpretación cósmica y reverencial; o vista como "lugar religioso", es decir, como un territorio de gran espiritualidad. El geógrafo griego Heraclides Crético en su descripción de Grecia destacaba que "en lo

\footnotetext{
En cierto modo, el ejercicio metodológico es inverso, se trabaja en desconstruir el sentido común, la racionalidad que se alza como totalizante y buscar nuevos puntos de vista que permitan visualizar territorialidades que se mueven en diversas y móviles escalas.
}

más alto de la cumbre del monte (montaña) se encuentra la gruta Ilamada Quironion y el templo de Zeus Acreo, en el cual (...) bajo el ardiente calor en su plenitud extrema, ascienden los más esclarecidos de los habitantes de la región y los más jóvenes; una vez que han sido sorteados por el sacerdote, son ceñidos con pieles de cordero nuevas, de triple grosor...". El mismo geógrafo hace referencia a la fecundidad en remedios medicinales de la montaña. (Garzón, 2008: 214). En China, también en tiempos antiguos, las montañas adquirían la calidad de divinidad, donde incluso se llevaban a cabo sacrificios (Tuan, 102). Diversas religiones orientales, por lo mismo, instalaron templos en ellas. La montaña, por tanto, no fue comprendida como un asunto extraño o una barrera inexpugnable $y$, junto a su majestuosidad física, ella estaba cargada o mediada bajo el hálito de un lenguaje mágico o religioso, parte importante de lo cual se reflejaba en la toponimia asociada a esos espacios de altura, donde primaban palabras como Sombra o Silencio y otras muy descriptivas como Cola de Pez, La Fortaleza de Nieve, El Lugar de los Santos o La Madre que Abraza (Vaidya, 1977).

Tal posición cambió con la cultura geográfica renacentista de la Europa del siglo XVI donde la idea del espacio se asoció a una naturaleza que se presentaba al hombre para su descripción, es decir, en vínculo con él. La tradición de la Ilamada Edad Media había, indirectamente, colaborado a este cambio al afirmar la creación de la tierra como morada de los descendientes de Adán y Eva ${ }^{8}$. Con ello, se negaba el concepto griego de ecúmene expresado en la teoría de las antípodas, que había sostenido la existencia de espacios propicios a la presencia humana separados por otros, cuyo carácter sagrado o inhabitable, hacía inviable la vida de los hombres. A este primer impulso, se sumó una incipiente desacralización del espacio (es decir, una mayor

\footnotetext{
8 El término Edad Media nos plantea un ejercicio similar al de montaña-frontera, ya que su definición es una imagen consolidada en el siglo XIX, justificada por los historiadores, donde se proyectaba un espacio de oscuridad y superstición por la ausencia de la ciencia o respuestas comprobables. Esta imagen colaboró a evidenciar, entre otros múltiples aspectos, la combinación de la "muerte de Dios" (Nietzsche) y la "invención del hombre" (Foucault).
} 
laicización de él), que reforzó la comprensión de la tierra como un continuo, un territorio abierto al hombre. De este modo, comenzó a dejarse atrás la naturaleza amenazante del período precedente domesticada por un predominio cada vez mayor de la fe en el hombre y su capacidad de dar explicaciones racionales. Por tanto, en este renovado contexto, los montes, las montañas o sierras formaban parte de esta tierra continua y abierta al hombre para la exploración, la descripción y la representación en mapas (Vega, 2005: 40).

Chile y América en general no estuvieron ausentes de aquel relevante cambio. En cierto modo, el descubrimiento de América, como ha sido llamado, no fue sino el viaje de la Razón a América: "La imagen del viaje, cual metáfora, debe asociarse al proceso de traspaso cultural a partir de las ideas ilustradas reinantes en Europa" (Núñez, 2009: 69). De esta suerte, la noción y visión del territorio en América, y por ende en Chile, fue una proyección o invento que surgió a partir de los mitos, visiones, creencias de quien las proyectaba ${ }^{9}$.

En este marco, por tanto, la noción de la montaña y la cordillera de Los Andes en Chile se vio fuertemente marcada por el proceso de racionalización asociado a la ilustración que, a grandes rasgos, se puede ubicar como maduro en el siglo XVIII. A partir de este siglo, en un proceso lento, pero continuo, fue cambiando el modo de comprender y usar el territorio. El control de territorio, su racionalización e institucionalización impuso al paisaje un horizonte que vino a cambiar la representación previa. Ello afectó y modificó, entre otros múltiples aspectos, la imagen de la montaña y de la cordillera de Los Andes.

Sin embargo, el equivalente absoluto de montaña y frontera política no fue una realidad firme sino muy avanzado el siglo XIX, incluso la primera del XX. Previo a ello, su identidad espacial se acercaba a lo que se ha denominado "espacio diverso, montaña

\footnotetext{
9 Un pionero en esta idea es el historiador mexicano Edmundo O'Gorman, La invención de América (1958), y Octavio Paz, quien se encarga de difundirla de modo más masivo en el increíble libro El laberinto de la soledad (1950), ambos tan antiguos como vigentes.
}

plural" (Núñez, 2009) y aquello se produjo porque su humanización definitiva no parece adquirir forma y fondo sino hasta la puesta en marcha efectiva del Estado-nación. De hecho, como apunta Invernizzi (1984), los relatos de cronistas y viajeros de los siglos XVI y XVII muestran en general una naturaleza de la abundancia, poseedora de la variedad, de la diversidad. Muchas de estas ideas se reflejaron en los cuestionarios y las crónicas oficiales, mas ellas también representan el medio chileno como ámbito en que se realiza una hazaña, como escenario épico.

En otras palabras, lo que es interesante desde la perspectiva de las escalas territoriales, la cordillera actuaba como una fuerza figurada o sensible, cuya presencia implicaba la manifestación de significados que solo "localmente" adquirían dimensión. Es decir, como imagen simbólica: "Los Andes se inserta dentro de los objetos más irresistibles, de suerte que por inepto que sea el que imagina una montaña, obtendrá rápidamente una conclusión sobre sus virtudes representativas. Si a esto se suma el vivir diariamente enfrentando a una montaña tan excesiva como son los Andes, el sujeto simbólico es sometido a una verdadera presión-obligación por representarla; un niño andino tiene que dibujarla, a menos como telón de fondo de cualquier paisaje natural o fantástico que trate de reproducir" (Mege, 1994).

La Figura $N^{0} 1$ da cuenta de aquel imaginario sensible -es decir, no racional- donde cordillera y ríos aparecen representados desde la diversidad y pluralidad espacial, con cuerpos de agua transcordilleranos y una montaña no uniformada o compacta, donde sobresalen numerosos planos o valles que no parecen poner término a un territorio respecto de otro más allá de ella. El territorio, además, es proyectado en un sentido oesteeste, es decir, con el Pacífico y la cordillera, junto a los ríos, como protagonistas. En otras palabras, una "región" que se percibe transcordillerana y en relación al este.

En la práctica, la cordillera de los Andes no fue una barrera infranqueable como ha sido planteado ${ }^{10}$. La cordillera era usada en

\footnotetext{
10 Puntualmente Sergio Villalobos. Historia del pueblo chileno. Tomo II. Editorial Universitaria. 1983.
} 
Figura $\mathrm{N}^{\circ} 1$

Descripción del Obispado de la Concepción y derrotero general de la visita que hizo el Sr. Presidente Don Joseph Manzo de Velasco

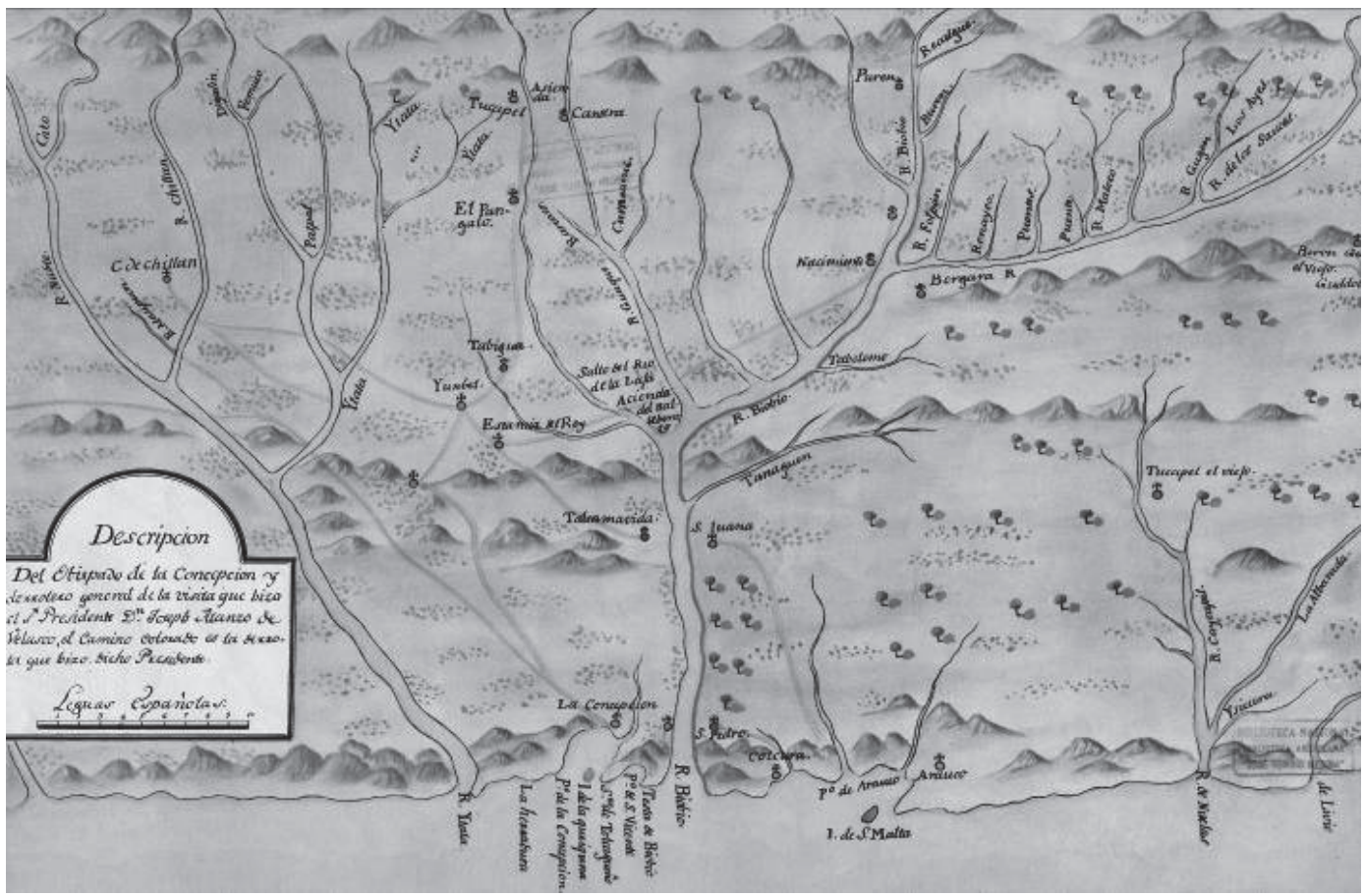

Fuente: José Toribio Medina. Cartografía Hispano-colonial de Chile. Santiago de Chile: Imprenta Universidad, 1924. Biblioteca Nacional.

forma recurrente y múltiple en sus diversos pasos, básicamente para el comercio con el mundo pehuenche, los contactos con Cuyo, con Buenos Aires y con otras zonas locales, como la zona del Maule, Araucanía, entre otras. En su representación es indispensable distinguir entre la territorialidad indígena, la ya mencionada territorialidad local y la proyectada desde el discurso de poder español $y$, posteriormente, republicano ${ }^{11}$. Desde este último punto de vista, la cordillera fue un elemento natural que colaboró con la definición de límites y, posteriormente, de frontera, obviando la serie de relaciones o circuitos existentes tanto en el mundo indígena como después en el espacio colonial y republicano. En esta línea, respecto a la zona de la Norpa-

${ }^{11}$ Los indígenas, del altiplano o de la cordillera maulina o de la Araucanía, dimensionaban un espacio móvil y una cordillera como parte integrante de su cosmovisión. Al respecto, Bengoa (2000). tagonia chilena-argentina, Bandieri expone: "Numerosas fuentes documentales han permitido reconstruir las sólidas relaciones socioeconómicas del área andina de Neuquén con las provincias del sur chileno, repitiendo formas heredadas de los grupos indígenas locales que hasta su definitivo sometimiento habían actuado como eficientes intermediarios entre las sociedades capitalistas de ambos lados de la cordillera" (2005: 347).

El territorio del siglo XVII, XVIII, pero también buena parte del XIX, fue, entonces, una "identidad múltiple", una pluralidad que contrastó con la uniformidad con que se fue ordenando a medida que avanzaba el propio siglo XIX. Para el caso de la cordillera, aquel "telón de fondo" que visualizamos en la actualidad.

De aquella pluralidad da cuenta Téllez (1990) al estudiar el espacio pehuenche y definir que la cordillera de los Andes, lejos de 
semejar un bloque compacto como es reflejada en el presente, "se anarquiza en una pluralidad de reducidas cordilleras transversales", representando una geografía complicada y diversa. Abundaban a los ojos de aquellos habitantes coloniales, los valles y pasos intercordilleranos, los típicos ríos torrentosos de la cordillera y, por cierto, la multiplicidad de bosques. Solo en la zona de la Pehuenía, del Laja al sur o Norpatagonia, se han identificado alrededor de 27 pasos que manifiestan la activa comunicación transversal entre grupos de indígenas de ambos lados de la cordillera, definiendo así el sentido del territorio: Buta Mallín, Leña Malal, Picunleo, Trapa-Trapa, Pucón Mahuida, de Rahue, de Pehuenco, de Pino Solo, de Pino Hachado, de Mallín de Icalma, de Icalma, de Llaima, Tres Picos, Pirihueico, entre otros (Ugarte, 1996). Muchos de estos pasos subsisten en la actualidad, algunos con carácter oficial y otros de uso tradicional.

\section{Fronteras políticas, fronteras diseñadas}

En el siglo XIX, el espacio se politiza en función de un poder estatal que se encamina a definir una racionalidad territorial de escala nacional. Al buscar configurar y delimitar un territorio, la cordillera de Los Andes y la frontera aparecen, entonces, en función de la institucionalización del espacio.

En ese marco, la frontera, como imaginario y discurso, comienza a adquirir la forma de un instrumento de poder, es decir, "la constatación de un Estado que posee un territorio sobre el que ejerce la soberanía. Este territorio, delimitado por una frontera, contiene a la ciudadanía sometida a dicha soberanía" (Nogué y Rufi, 2001: 69).

La percepción del concepto de frontera requirió y se justificó, por tanto, en un sentido de línea, representación social que, en definitiva, fue un "borde" consustancial al cuerpo cierto que era el Estado-nación: "La frontera fue el órgano periférico estatal inherentemente unido a la existencia de los Estados nacionales. Desde este punto de vista, la frontera era el resultado de una dialéctica histórica que producía la creación de una franja defensivo-ofensiva que concentraba a las fuerzas enfrentadas de cada Estado. Esta idea fue desplegada e incorporada como un elemento clave en el pensamiento geopolítico argentino en las primeras décadas del siglo XX" (Hevilla, 2001: 44).

La producción de un borde fronterizo se sumó al despliegue de una serie de formas de racionalización que buscaron también definir un determinado tipo de proyecto territorial. Estos dispositivos o estrategias se iniciaron el siglo XVIII y con mayor fuerza en los siglos siguientes, escenario que fue válido tanto para Chile y Argentina como para el horizonte común latinoamericano. Se trataba de construir, en tanto nación, formas de identidad colectivas, entre las que era identificable una de alcance espacial: el territorio de la nación ${ }^{12}$. La modernidad, por tanto, terminó por desplazar los límites del espacio hacia un panorama más amplio, por lo que "el espacio, debido al movimiento de circulación de personas, mercancías, referentes simbólicos, ideas, se dilató (...) Presupuso el desdoblamiento del horizonte geográfico, al retirar a las personas de sus localidades para recuperarlas como ciudadanos. La nación las desencajó de sus particularidades, de sus provincianismos, y las integró como parte de una misma sociedad. Los hombres, que vivían la experiencia de sus lugares, inmersos en la dimensión del tiempo y del espacio regionales, fueron así referidos a otra totalidad" (Ortiz, 2002: 82). Aquella totalidad y dilatación territorial actuó, en el fondo, como referente para "la construcción de la comunidad imaginada": "La invención del territorio es entonces no solo necesaria para los fines económicos sino también a los fines simbólicos (...) la formación del Estadonación argentino fue un proceso planificado que implicó la 'invención' de un territorio 'legítimo' sobre el cual era posible ejercer el dominio, entendiendo por invención la existencia de un proyecto político 'a priori' al ámbito geográfico que será de dominio del Estado..". (Zusman y Minvielle, 1995: 2).

De esta manera, como indican las citadas autoras, la tesis que establece que un cierto territorio le pertenece de manera natural a

\footnotetext{
12 Para el caso argentino, entre otros, ver Navarro Floria (2004); Bandieri (2009) y Lois (1997).
} 
una nación es solo consustancial a los discursos o representaciones de poder de los que imaginaron la nación. Al respecto, la generación de conocimiento científico que respalde las decisiones de orden político llevó a que el objeto-territorio se transformase en un objeto político, un asunto donde la Geografía no estuvo ausente: "La Geografía, en consecuencia, fue el campo disciplinario legitimador de las nacionalidades, de los proyectos nacionales, de los sentimientos patrióticos y de las identidades espaciales, no creando sino apropiando, sistematizando, escolarizando y naturalizando la reflexión estatal sobre la identidad territorial" (Moraes, 1991, citado en Navarro Floria, 2007: 14)

Desde otra perspectiva, la definición de la territorialidad de la nación y con ella de la frontera, fue un proceso de configuración del espacio que no solo fue un asunto físico o geográfico, es decir, el hecho de anexar tierras así como la definición del límite fue un escenario con un trasfondo social relevante, en tanto, determinadas relaciones sociales (agentes sociales) implicaron, a su vez, relaciones espaciales (Sánchez, 1979). Este punto es importante: las acciones asociadas a la definición de la territorialidad de la nación estaban -y están- cargadas de intención, de propósitos, todas proyectadas desde una estructura social, normalmente vinculada a valores forjados desde el ámbito de poder: “De esta forma, la articulación del espacio no obedecerá exclusivamente a causas geográficas, sino que estará en relación, dependerá, del poder; es decir, el medio es manipulado por el poder para ponerlo a su servicio en cada momento" (Sánchez, 1979) ${ }^{13}$.

Con este importante cambio de escenario, la cordillera de Los Andes sufrirá la mutación de sentido, es decir una metamorfosis, que será de gran utilidad a un espacio consustan-

\footnotetext{
$13 \mathrm{Al}$ respecto es interesante el planteamiento de Michel de Certau quien formula que el hombre común, a través de sus prácticas cotidianas, "se reapropia del espacio organizado por los técnicos de la producción sociocultural", lo que supone una suerte de reinvención frente al sometimiento absoluto que, de acuerdo a Foucault cada conocimiento institucionalizado impone a los hombres. Para un caso, La invención de lo cotidiano. (2000) y para el otro Vigilar y castigar (2002).
}

cial a las necesidades de aquella articulación e institucionalización espacial a partir del poder estatal, es decir, a la configuración de una territorialidad de alcance fronterizo ${ }^{14}$.

La frontera del país Ilamado Chile, por ende la cordillera de Los Andes, comenzó, por tanto, a comprenderse en relación a un "otro", Argentina y Bolivia, por ejemplo, y, por lo mismo, ella se posicionó en una orientación vertical (línea que corre paralela entre dos territorios-nación entendida en disposición norte-sur (o viceversa), imaginario, simbólico y material, resultante, como expresamos, de la construcción de territorios homogéneos a partir de la configuración de la nación en el siglo XIX (Núñez, 2009, 2012).

A los dispositivos de control territorial impulsados por los borbones durante el siglo XVIII, el imaginario territorial de la nación en construcción fabricó los propios, aunque muchos de ellos fueron la continuación de aquellos. Entre las estrategias de poder que colaboraron a fijar el sentido de nación en un Chile más unitario, a las que hay que sumar el diseño de la frontera, se encuentran: (1) el control de los "espacios vacíos", es decir, la creación de nuevos asentamientos y espacios urbanizados con el fin de controlar distancias y, a través de ellas, al territorio; (2) la búsqueda y acumulación de información, que en el fondo fue una continuación de los cuestionarios borbónicos, en lo que podría denominarse un verdadero catastro de los bienes existentes en el territorio asociado a la nueva nación; (3) la exploración de nuevos territorios, en tanto la nueva nación necesitaba definir su marco territorial, para lo cual era indispensable explorar como sustento para la incorporación de nuevos espacios; (4) la supremacía simbólica de la ciudad sobre lo rural, lo que, como en otras latitudes, co-

\footnotetext{
14 El poder estatal no es abstracto, es racionalizado por grupos a partir de una práctica de gobernar: "Gobernar un Estado será, pues, poner en práctica la economía, una economía a nivel de todo el Estado, es decir, tener con respecto a los habitantes, a las riquezas, a las conductas de todos y cada uno, una forma de vigilancia, de control, no menos atenta que la del padre de familia sobre todos los de la casa y sus bienes" (Foucault, 1999b, 182). La frontera, entonces, era la tarea ineludible a fin de "cercar" el hábitat de la familia-nación.
} 
laboró a fijar en lo urbano el dominio de un discurso hegemónico; (5) la conformación de una historia nacional que diese sentido a sus habitantes, una perspectiva que generó mitos y héroes comunes, impactando en la memoria de la nación y en su necesidad de mirar un futuro, fruto de su propia tradición; (6) la materialización del telégrafo, que colaboró a minimizar distancias; (7) del correo, que hizo que la temporalidad sufriera cambios de valorización y sentido; (8) mejoramientos de caminos y puentes, representantes del, como ha dicho Navarro Floria (2007), paisaje del progreso; y (9) la implementación del ferrocarril, tal vez la más simbólica de los dispositivos de control, por enumerar algunas de aquellas estrategias.

Aquella producción ideológica de la "cultura nacional" o comunidad, siguiendo a Anderson (1993), ha tenido efectos territoriales claros, impactos a veces complejos, como el rol que jugaron en aquella proyección los grupos aborígenes, simplemente marginados en el contexto de aquella necesidad de homogenizar e integrar social y territorialmente a la nación. Pero más allá, ha permitido invisibilizar y minimizar una serie de intereses y relaciones que surgen en espacios fronterizos, muchos de ellos, cargados de historicidad y memoria no asimilables a la escala "nacional". Un claro ejemplo de aquella historicidad y particularidad territorial es posible observarla en el amplio espacio Norpatagónico chileno-argentino, espacio cultural cuyo relato de memoria se ha encargado, entre otros, de mostrarnos la historiadora argentina Susana Bandieri (1993, 2003, 2005, 2005b, 2009). Desde esta perspectiva, serán consustanciales al Estado no solo preocuparse por la territorialidad soberana de la nación y por la existencia de una institucionalidad vigorosa y coercitiva sino que, este aspecto es clave en el desarrollo de los imaginarios territoriales, alimentar una noción colectiva que defina un "nosotros":

"A nosotros nos basta con establecer esas fronteras en nuestras mentes; así pues, ellos pasan a ser ellos y tanto su territorio como su mentalidad son clasificados diferentes de los nuestros... A las fronteras geográficas les siguen las sociales, étnicas y culturales de manera previsible" (Said, 87).
La sociedad estatal actúa bajo la lógica de una actitud de imposición del o los valores asociados a aquel "nosotros". Este "nosotros" queda definido, por tanto, como verdad y representa el horizonte cultural a través del cual desplegamos sentidos de lo que se transforma en real y lo que no: "Para el caso del occidente industrial, aquella hegemonía cultural ha resultado muy evidente, al proyectar el mundo de los "ellos" (otros) desde la óptica de un "nosotros" (Said, 27) 15 .

Se han dibujado en aquellos espacios menores fronteras no asimilables a la "escala nacional". De ello nos encargaremos en el siguiente y último punto. Es necesario, sin embargo, aclarar un aspecto sustancial: que la frontera Norpatagónica haya tenido intercambios permanentes y fluidos hasta al menos fines de la década del 30 del siglo XX (Benedetti, 2005) y que en la actualidad aquellos contactos se revivan a partir del turismo, no implica que las fronteras de escala regional no hayan vivido tensión o presenten nuevas y marcadas formas de nacionalismo de una parte y otra. No sugiere, como lo ha resaltado adecuadamente Grimson (2000b), que ellas respondan a una suerte de imagen romántica donde unos y otros son hermanos y la frontera política rompe aquella fraternidad. Las fronteras son diversas, cambiantes, precisamente como expresamos páginas atrás, porque ellas, como otros espacios geográficos, manifiestan una historicidad peculiar. Como plantea el propio Grimson (2011: 177) "visualizar las fronteras del mundo -sus literaturas, sus películas, su vida cotidianaequivale a hacerse de un caleidoscopio".

\section{Norpatagonia en el caleidoscopio: frontera cultural, territorialidad dinámica, imaginarios múltiples (siglos XVIII, XIX, XX)}

Los estudios de historia regional muchas veces han sucumbido al protagonismo de las

\footnotetext{
15 Michael Foucault lleva el asunto del poder a una posición ontológica, determinando, en consecuencia, que la producción cultural es inherente al poder.
} 
Figura $N^{\circ} 2$

La Norpatagonia comprende las actuales provincias de Río Negro y Neuquén (Argentina) y las regiones de La Araucanía, Los Ríos y Los Lagos (Chile)

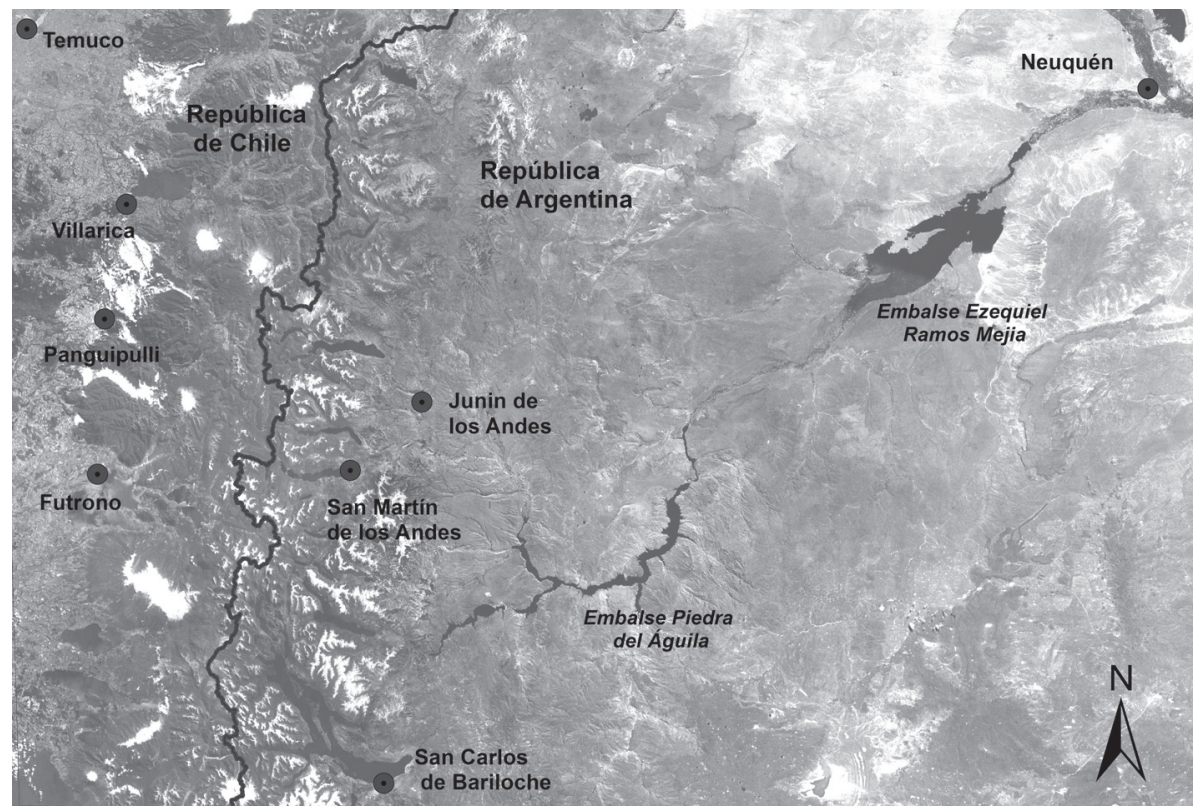

Fuente: Elaborado por Paulina Gatica.

historias nacionales. A su vez, las territorialidades regionales y sus procesos de significación y cambio, han sido desdibujados por aquella racionalidad territorial de alcance nacional. Sin embargo, esas historias y sus territorialidades resultan claves cuando se requiere indagar y "acceder al conocimiento de la riqueza y dinamismo que encierran las áreas de frontera, entendidas como verdaderos espacios construidos en procesos históricos de larga duración" (Bandieri, 2007). Al trabajar "más de cerca" encontramos que nuevas perspectivas surgen a la vista. Una de ellas es la constatación de una montaña viva y compleja, cargada de movilidad y presencia, cuya sociabilidad la aleja de la posición de índole político y mayormente difundida de "línea fronteriza".

En esa escala menor, la cordillera de Los Andes en la zona denominada Norpatagonia (Figura $\mathrm{N}^{\circ}$ 2) presenta una historia territorial fronteriza particular ${ }^{16}$. En primer término, desde una perspectiva histórica, se trata de una región con una definición administrativa tardía, cuya significación se articula en una relación distinta de la construcción nacional, no necesariamente en oposición a ella, sino como territorialidad, es decir, como "construcción simbólica que se hace en relación con un referente" (Ortiz, 2002: 60 y 77). El asunto es clave, ya que aquella región se fue desenvolviendo en gran parte en relación a referentes que no tenían que ver con la nacionalidad y, además, y por lo mismo, se construyó según perspectivas tanto de un lado de la cordillera y otro (chilenos y argentinos). Bajo esa matriz, la montaña, actuó no

\footnotetext{
${ }^{16}$ Actuales provincias de Río Negro y Neuquén, en Argentina y regiones de La Araucanía, Los Ríos y Los Lagos en Chile.
} 
como elemento separador o barrera, sino, al contrario, como espacio articulador, donde se desplegaron vínculos que fijaron sujetos sociales específicos ${ }^{17}$. Siguiendo al ya citado Anderson (1993), podríamos decir que la Norpatagonia fue en sí una comunidad imaginada, proyectada en forma independiente de la organización espacial del Estado-nación, al menos hasta la década del 30 del siglo XX, cuyas referencias estuvieron durante largo tiempo en un sentido este-oeste, es decir, en una posición territorial donde la cordillera de Los Andes era parte central de la construcción identitaria de la zona.

Numerosos estudios, precisamente de escala regional, han mostrado el carácter poroso, social y referencial de la cordillera. Entre otros es posible mencionar a Bandieri (2005), Benedetti (2005), Navarro Floria (2007, 2011), Pinto (1996), Tozzini (2004), Bondel (2008), Valverde, et al. (2011), Bello (2011), Flores (2006). En general, todos ellos dan cuenta del sentido relacional del espacio fronterizo. Unos fundan su análisis desde la lógica de las articulaciones económicas, otros desde el ámbito etnohistoriográfico y otros desde una visión antropológica, por nombrar algunas perspectivas de análisis.

Lo que es claro, como muchos coinciden, es que los vínculos transfronterizos de la Norpatagonia fueron permanentes en el tiempo, desde el siglo XVII hasta muy avanzado el siglo $X X$, incluso, aunque se trata de contextos distintos, procesos migratorios de chilenos a Argentina continuaron, con distintas fluctuaciones, en las décadas del 50, 60 y 70, prolongándose muchos de ellos hasta la actualidad (Matossian, 2010). Como indica Pinto (1996), la solidez del mundo fronterizo, cordillera de Los Andes mediante, persistió en la Norpatagonia incluso al proceso de racionalización territorial de los Borbones durante el siglo XVIII así como al proceso independentista. Una característica relevante de toda esta larga época fue la interrelación y complementariedad de "las redes indígenas

\footnotetext{
17 Esta visión se refiere a una región "como elemento de estructuración social que articula tiempo y espacio y condensa diferentes procesos sociales que implican el desarrollo de una territorialización de las relaciones histórico-sociales" (Bandieri, 2007, 49).
}

con las capitalistas" que alejadas del centro se desenvolvían en una lógica específica, con códigos propios (Pinto, 1996). Entre otras razones, aquello se dio así por

"la marginalidad del territorio con respecto al mercado nacional y al modelo de desarrollo basado en la exportación de bienes primarios con fuerte orientación atlántica, la perdurabilidad de las relaciones comerciales con el sur chileno, la incomunicación con otros mercados regionales del país, la persistencia de aéreas productivas de subsistencia y la escasa generalización de las formas capitalistas de producción, así como la débil presencia del Estado nacional en la región..." (Bandieri, 2005: 70).

Del lado chileno, la relación con las pampas argentinas perduró hasta que la ampliación de las fronteras productivas, impulsadas desde el Estado en el último cuarto del siglo XIX ante la necesidad de contar nuevas tierras para explotación de trigo así como a la necesidad de control de los territorios indígenas, vinieron a cambiar el panorama (Carmagnani, 1984).

En el marco de este horizonte históricocultural, la cordillera de los Andes fue un símbolo de traspaso, de encuentro -no, como dijimos, en el sentido romántico- de acceso más que de barrera. Su imagen, por tanto, más allá de las dificultades propias de espacios de montaña, debe comprenderse en un marco de significación de transferencia cultural de escala regional ajena a la homogenización nacional surgida durante el siglo XIX. Como acertadamente expresa Cavieres:

"Cuando en nuestras relaciones argentinochilenas aparece la imagen de la cordillera de los Andes como una frontera natural separadora de sendas alteridades sociales, culturales, económicas y de esencias nacionales, debe recordarse que esa imagen fue una construcción articulada y generalizada por los mismos Estados nacionales" (2005: 21).

Desde esta perspectiva, las fronteras impuestas por los poderes centrales hicieron caso omiso de la historia y procesos que en la escala regional se desarrollaban, procedién- 
dose a escribir una (nueva) historia -esta vez sí escrita y difundida, Ilamada paulatinamente historia nacional- que tuvo como punto de origen el establecimiento de la soberanía en la zona de la Norpatagonia en detrimento la trayectoria y memoria de las poblaciones locales, junto con sus intereses y los significados que le daban a su entorno. A esto Bandieri le ha llamado el proceso de desestructuración de la región (2005: 348).
La figura $\mathrm{N}^{\circ} 3$ es ilustrativa de aquella idea. La foto es actual y remite al valle El Manso en la frontera norpatagónica chilenoargentina. La casa, que data de 1899, existía previa al hito fronterizo instalado por el Estado a principios del siglo XX. Es decir, simbólicamente hablando, una parte de ella es argentina y la otra es chilena.

Figura $\mathrm{N}^{\circ} 3$

Casa ubicada en el valle El Manso en la frontera norpatagónica chileno-argentina

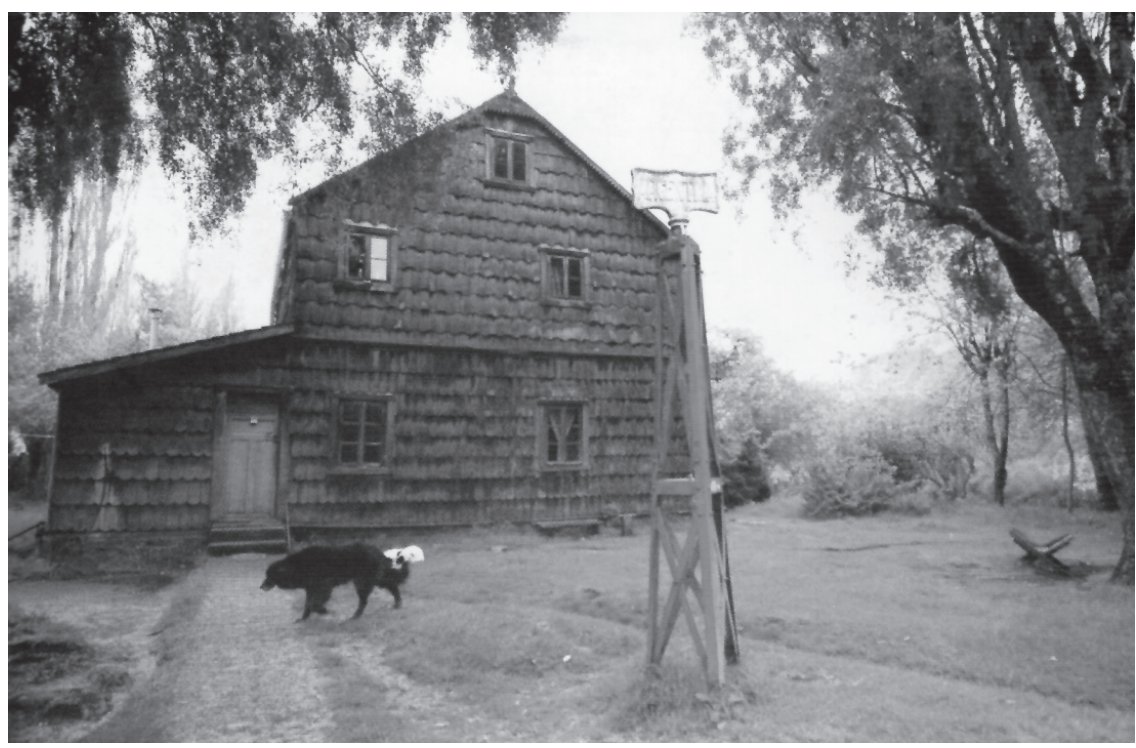

Fuente: Imagen incluida en el artículo de Xicarts et al., 2011. Gentileza de sus autores.

A partir de la irrupción de una frontera de alcance nacional, la cordillera de Los Andes mutó su representación en una (re) significación que la marcaba como "natural". En 1895, el influyente diplomático e ingenierogeógrafo, Eduardo de la Barra manifestaba, emulando a Dios, que "la Naturaleza puso entre ambas naciones (Chile y Argentina) la gran cordillera nevada de Los Andes para dividir sus tierras y sus aguas, por la "raya" imborrable de la cumbre" (1895: 49). En otras palabras, proyectaba en la cordillera un hito impuesto por la naturaleza para definir a las naciones.
Aquel punto de vista, es decir, que el territorio de la nación era un elemento congénito e inherente a la nación, se hizo estructural en la época y muchos estudios y funcionarios de gobierno se encargaron de estamparlo como oficial, tanto de un lado de la cordillera como del otro.

En efecto, aquella interpretación se fue consolidando en la larga búsqueda de hitos que definiesen las fronteras nacionales, un proceso que tomó varias décadas, partiendo por los tratados de 1881 y 1893 para el caso de Chile y Argentina. Remitiéndose a nume- 
rosas fuentes coloniales y otras de científicos del siglo XIX, ambas basadas en lecturas de carácter positivista o naturalista de la cordillera, esta era hacia 1902 definida como "cumbre", "muralla", "raya", "cadena de gran elevación", "compacta en su encadenamiento", entre otras acepciones. Incluso el propio Diego Barros Arana, historiador chileno y encargado de las negociaciones de fijación de límites, expresaba, con notoria exageración, que "es la cadena misma del Himalaya la que se parangona con la cordillera de Los Andes..." (Argentina, 1902: 89). En el proceso de definición de la frontera, era, por tanto, necesario reafirmar lo que era físicamente evidente: que la cordillera era una barrera imponente.

El proceso de la instauración de la frontera política fue lento. Como expresamos, una serie de otras acciones llevaron a que la fronterización de la montaña madurara y finalmente colaborara a invisibilizar la cordillera de Los Andes desde una perspectiva sociocultural. En efecto, en paralelo al avance de las fronteras productivas en Chile y la ocupación de la Araucanía por parte del ejército nacional, ambas insertas en los modos de producción capitalista y, por otra parte, de la imposición de los Territorio Nacionales así como el avance del ferrocarril en Argentina, la Norpatagonia mantuvo una interculturalidad, un lenguaje territorial y una historicidad, al menos no discursivamente nacional ${ }^{18}$. No es, como bien aclara Grimson (2011: 113), que en ella solo hubiese habido intercambio armónico sin cambios o sin conflictos, pero lo que es notorio es que ellos no eran de escala nacional y funcionaban en una lógica Oeste-Este y viceversa, por lo que se asentaban, por tanto, en una amplia zona que hoy podemos denominar Norpatagonia. Parafreseando a Grimson (2011: 126), la región se presentó como una "heterogeneidad cultural" en un ámbito territorial común.

\footnotetext{
18 Lo mismo que para Argentina, otra arista del mismo problema, es el avance del ferrocarril a las zonas de la región norpatagónica, es decir, Neuquén y Araucanía. El ferrocarril se transforma, desde esta perspectiva, en un dispositivo simbólico y material de avance en el marco de una producción capitalista (Ver Núñez, 2009).
}

El espacio cordillerano de la Norpatagonia se resignificó con el tiempo, en tanto "el Estado y la nación fueron incorporados a las categorías y a las prácticas nativas" o precedentes:

"Durante la década de 1880 los ejércitos de ambos países lograron someter a las poblaciones indígenas de la región cortando la tradicional comunicación entre la Araucanía y las Pampas. El éxito de las operaciones militares permitió consolidar unidades territoriales nacionales interrumpidas hasta allí por la existencia de territorios indígenas. Expropiados estos a sus dueños originarios se impuso a la región una frontera, la cordillera de Los Andes, como límite geográfico y político. Sin embargo, la organización social de las áreas fronterizas continuó actuando casi inalterablemente, por encima de la imposición de tales límites. La red de intercambios económicos y demográficos entre ambos lados de la cordillera se vio favorecida durante años por el predominio de los acuerdos entre los dos países, donde primó la fórmula de cordillera libre" (Bandieri, 1996: 182).

Es decir, aquella cordillera integrada a la región binacional no detuvo su movilidad y dinámica sino hasta muy avanzado el siglo $\mathrm{XX}$.

En 1914 según el censo de la época en el Territorio Nacional de Neuquén el $61 \%$ de la población era chilena (Torres, 2005: 427). Como expresamos párrafos atrás, recientes investigaciones han demostrado la existencia de una relevante movilidad transfronteriza en las décadas de 1950 y 60, especialmente Matossian (2010). En palabras de Benedetti:

"A lo largo de la cordillera de los Andes, lugares de frontera fueron cobrando forma y sentido a lo largo del siglo XX. Sin embargo pareciera difícil hablar de fronteras como 'barreras' a la circulación hasta la década de 1920/1930, ya que los controles a la movilidad eran reducidos o nulos. Esto no significa que no existiera ninguna clase de control y que la movilidad transfronteriza estuviera completamente liberada a los intereses regionales, sino que hasta entonces no hubo una clara milita- 
rización de la frontera, como empezó a ocurrir hacia fines de la década de 1930" (2005: 206).

Un dato que para el caso de la Norpatagonia chileno-argentina reafirma ese punto de vista es que ya avanzado el siglo $X X$, el comercio de la provincia de Neuquén en Argentina se realiza vía Pacífico, además de la importante población chilena al lado este de la cordillera. Así,

"la conexión con Chile es percibida entonces como una realidad muy importante sobre comienzos de la década de 1920, favorable en ciertos aspectos -sobre todo por la potencialidad de su mercado, que motiva incluso la sugerencia de cambiar la capital- y desfavorable en otros, especialmente en lo que hace a la falta de "sentimiento de argentinidad" en el territorio" (Bandieri, 2005: 360).

Tal situación se explica, en tanto los procesos de construcción territorial suponen un proceso simbólico de representación cuya materialización toma tiempo en objetivarse. Desde esta perspectiva, como lo fue para la territorialidad indígena, la cordillera mantuvo su condición plural en tanto los circuitos económicos entre Chile y Argentina no se desconectaron en la práctica y las relaciones personales mantuvieron su impronta (Policastro, 2011: 227). Solo con una activa institucionalización de la montaña, ella adquirió una resignificación de barrera y frontera, a tal punto

Figura $\mathrm{N}^{\circ} 4$

Producción de paisajes limítrofes

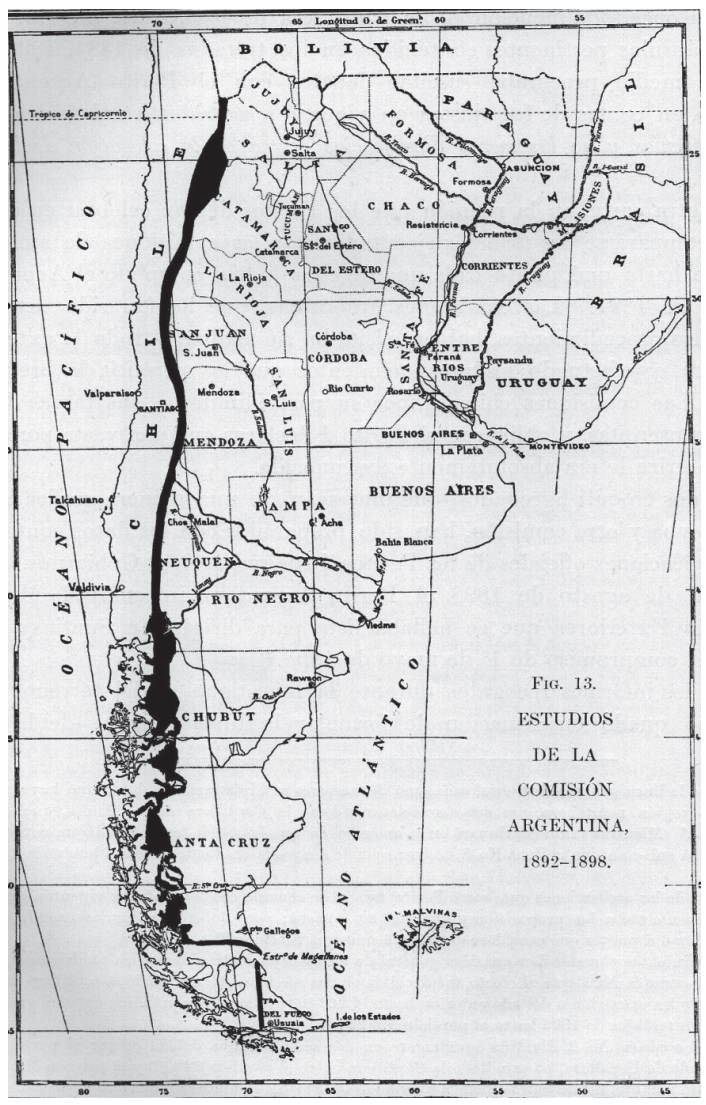

Fuente: Argentina. Oficina de Límites, 1902. 
que llevó, representación aún sólida, a que, volviendo a nuestra metáfora, la frontera no deje ver la montaña.

En definitiva, cuando hacia la década de 1930 la producción del imaginario territorial de la frontera política por parte del Estado, es decir, de la frontera como línea, adquiere perspectiva y solidez, suceden tres situaciones que interesa resaltar. La primera, que del mismo modo que la nación se construyó un relato de una historia común, a partir de lo cual surgieron numerosas Historias de Chile y Argentina, ella, la nación también ideologizó el territorio, fijando en el espacio "nacional" una imagen universal, amplia y general, todo lo cual fue plasmado en una cartografía oficial que colaboró a dar sentido e identidad a los habitantes y a partir de lo cual, la cordillera pasó a representar el límite político, valor que aún mantiene. Aquella producción de paisajes limítrofes (Figura $N^{\circ} 4$ ) así como el carácter homogéneo del espacio bajo un horizonte nacional no permitió dar cuenta de una multiplicidad cultural y territorial de indeterminados espacios de escala menor.

En forma paralela, como segundo escenario a destacar, la Norpatagonia a partir de lo anterior se fue reterritorializando y reconstruyendo en torno a un nuevo sentido identitario, esta vez influido y marcado por el sentido nacional de los territorios fronterizos, donde se entregaron propiedades y numerosas concesiones a nuevos habitantes en la zona andina, muchos de ellos extranjeros (Risopatrón, 1907: 111 y ss.). En la fabricación de aquella nueva representación, se desplegaron numerosas tareas, entre otras, una nueva productividad para el área, creación de Parques Nacionales, una valorización de colonización de aquellos territorios, una conectividad indispensable y la difusión de un conocimiento más acabado de lo que era pertenencia (Chile), de lo que era alteridad (Argentina):

"Las prácticas de conquista y exploración del territorio, personificadas en el Estado y en instituciones funcionales a él, constituyen una secuencia lógica y metodológica de operaciones por las cuales se ponía en juego el instrumental técnico y conceptual de la apropiación del espacio, se estructuraba una representación del espacio y del tiempo y se organizaba la realidad regional misma" (Navarro Floria, 2007: 58).

Finalmente, la chilenización, así como la argentinización de aquellos territorios norpatagónicos, aunque de muchos otros, homologó las diferencias trazando nuevas interpretaciones y lecturas para un espacio tan amplio como el cordillerano. Nuevas prácticas, nuevas identificaciones, nuevos sueños y proyecciones se fijaron en torno a este renovado espacio fronterizo. Los sujetos sociales se adaptaron y reprogramaron a la nueva identidad coyuntural que surgió en torno a la nación, un referente que, en definitiva, los resignificó cultural y territorialmente.

\section{Consideraciones finales}

En la actualidad la globalización ha causado gran impacto en las distancias, comunicaciones y fronteras. Las comunicaciones son tan rápidas y efectivas que existe una sensación de unión total o muy grande. Paralelamente, a partir de aquel proceso, muchos Estados-nación se han privatizado o, al menos, disminuido su tamaño a tal nivel que la línea entre producción pública y privada se torna muy delgada y en muchos casos, como en Chile, la balanza se inclina ostensiblemente en relación a la segunda. Lo anterior ha llevado a plantear a algunos autores, entre otros a la socióloga Saskia Sassen (2001), que los territorios se van desnacionalizando y que las fronteras adquieren un doble estándar si se trata de capitales o migraciones ordinarias.

A nivel escalar, por tanto, parece ser que nos enfrentamos a un nuevo proceso que distorsiona y desfigura producciones sociales y territoriales cuya certeza parecía estar resuelta. Nos referimos, por supuesto, al Estadonación. Hoy, el Estado-nación, en definitiva, como antes la Norpatagonia respecto de la nación, se relaciona y referencia en vínculo a una mundialización que integra y homogeniza las costumbres y culturas. En algunos ámbitos incluso se habla de una "cultura de la globalización", lo que nuevamente lleva a remitirnos al siglo XIX cuando los nacientes Estados-nación destacaban también imaginarios universales como el de la "cultura de la nación", muchas veces asentada en la búsqueda de una "cultura del progreso" o 
"cultura de la civilización", como un todo, un solo cuerpo, cuyos valores se tornaban tan amplios como ideológicos.

Lo anterior nos lleva, interés del texto, a poner en duda afirmaciones de índole universal en tanto no todo está globalizado ni el mundo es una sola cultura. Sin duda, objeto de numerosas investigaciones, persisten y subsisten "culturas menores" o menos oficiales, como lo fue la región de la Norpatagonia respecto de un territorio de alcance nacional. Como expresamos, incluso al interior de aquella Norpatagonia perduraron identidades que fueron en el tiempo replanteando su sentido, es decir, no fueron en ningún caso fijas.

La escala nacional, desde nuestra perspectiva, buscó homologar y definir un sentido común, frente a lo cual la incorporación y definición de territorios fue crucial. Para ello, por ejemplo, fue de gran utilidad la producción de Historias de Chile y Argentina, el desarrollo de modos de producción capitalista así como la valorización de una geopolítica vinculada al aparato estatal. La globalización, en la misma lógica, nos remite a un capital de alcance mundial, cuyo modo de producción colabora a unificar el, precisamente, mundo, transformándose, como para el siglo XIX lo eran el "desarrollo" y el "progreso", en una figura teleológica de amplio alcance.

La globalización, por tanto, desde su postura ideológica y política, invisibiliza una serie de manifestaciones de escala menor, cuya representación frente al mundo no solo es disímil y móvil sino también menos oficial. Del mismo modo, la interpretación dominante de una cordillera cuya única función es la de "línea" o "raya", de base política, es el resultado de una producción histórica y social que ha terminado por minimizar un amplio espacio social de montaña como lo es la cordillera de Los Andes.

\section{Referencias bibliográficas}

ANDERSON, B. Comunidades imaginadas. México: Fondo de Cultura Económica, 1993.

ARGENTINA. OFICINA DE LÍMITES. Memoria presentada al tribunal nombrado por el Gobierno de su majestad Británica para considerar e informar sobre las diferencias suscitadas respecto a la frontera entre las Repúblicas Argentina y Chilena. Londres: WiIliam Clowes Ltda., 1902.

BANDIERI, S. La persistencia de los antiguos circuitos mercantiles en los Andes Meridionales. En: MANDRINI, R. y PAZ, C. (editores). Las fronteras hispanocriollas del mundo indígena Latinoamericano en los siglos XVIII-XIX. Un estudio comparativo. Buenos Aires: IEHS (UNCPBA)-UNS-CEHIR (UNCo.), 2003, p. 253-286.

BANDIERI, S. (compilador). Cruzando la cordillera... La frontera argentino-chilena como espacio social. Neuquén: CEHIR-UNco, 2005a.

BANDIERI, S. Historia de la Patagonia. Buenos Aires: Sudamericana, 2005b.

BANDIERI, S. Estado nacional, frontera y relaciones fronterizas en los andes norpatagónicos: continuidades y rupturas. En: BANDIERI, S. (compiladora). Cruzando la cordillera... La frontera argentino-chilena como espacio social. Siglos XIX y XX. Neuquén: CEHIRUNCo, 2005c, p. 345-374.

BANDIERI, S. Nuevas investigaciones, otra historia: la Patagonia en perspectiva regional. En: FERNÁNDEZ, S. Más allá del territorio. La historia regional y local como problema. Discusiones, balances y proyecciones. Rosario: Prohistoria Ediciones, 2007, p. 47-72.

BANDIERI, S. Cuando crear una identidad nacional en los territorios patagónicos fue prioritario. Revista Pilquén, 2009, № 11, p. 1-10.

BELLO, A. Nampülkafe. El viaje de los mapuches de la Araucanía a las pampas argentinas. Territorio, política y cultura en los siglos XIX y XX. Temuco: Ediciones UC Temuco, 2011.

BENGOA, J. Historia del pueblo mapuche (Siglos XIX y XX). Santiago de Chile: LOM Ediciones, 2000.

BENEDETTI, A. Un territorio andino para un país pampeano. Geografía histórica del Territorio de los Andes (1900-1943). Buenos 
Aires: Tesis Doctoral de Geografía de la Facultad de Filosofía y Letras, Universidad de Buenos Aires, 2005.

BONDEL, S. Transformaciones territoriales y análisis geográfico en ámbitos de montaña. La comarca andina del paralelo 42. Buenos Aires: Tesis Doctoral de Geografía de la Universidad Nacional de La Plata, 2008.

BOURDIEU, P. Cosas dichas. Buenos Aires: Gedisa, 1988.

CARMAGNANI, M. Estado y sociedad en América Latina. Barcelona: Crítica, 1984.

CAVIERES, E. Espacios fronterizos, identificaciones nacionales y vida local. Reflexiones en torno a estudios de casos en la frontera argentino chilena. La revalorización de la historia. En: BANDIERI, S. (coordinadora). Cruzando la cordillera. La frontera argentino-chilena como espacio social. Neuquén: Universidad Nacional del Comahue, 2005, p. 1530.

DE CERTAU, M. La invención de lo cotidiano. México: Universidad Iberoamericana, 2000.

DE LA BARRA, E. El problema de los Andes. Buenos Aires: Coni, 1895.

ESCOLAR, D. Identidades emergentes en la frontera argentino-chilena. Subjetividad y crisis de soberanía en la población andina de la provincia de San Juan. En: GRIMSON. A. (compilador). Fronteras, naciones e identidades. La periferia como centro. Buenos Aires: Ediciones CICCUS-La Crijía, 2000, p. 256-277.

FLORES, J. Economías locales y mercado regional. La Araucanía, 1883-1935. Revista Espacio Regional, 2006, № 3, p. 11-28.

FOUCAULT, M. Saber y verdad. Madrid: Serie Genealogía del Poder, 1991.

FOUCAULT, M. Obras esenciales: Estrategias de poder. Vol. 2. Barcelona: Paidós. 1999a.

FOUCAULT, M. Obras esenciales: Estética, ética y hermenéutica. Vol. 3. Barcelona: Paidós, 1999b.
GADAMER, H.G. Verdad y Método. Salamanca: Ediciones Sígueme, 1999.

GARZON, J. Geógrafos griegos. Oviedo: KRK Editores, 2008.

GEERTZ, C. La interpretación de las culturas, México: Gedisa, 1987.

GRIMSON, A. (compilador). Fronteras, naciones e identidades. La periferia como centro. Buenos Aires: Ediciones CICCUS-La Crujía, 2000a.

GRIMSON, A. La fabricación cotidiana de la frontera política. Texto enviado al encuentro de la Asociación de Estudios Americanos, 2000b. Disponible en internet: http://lasa. international.pitt.edu/Lasa2000/Grimson.pdf

GRIMSON, A. Los límites de la cultura. Crítica de las teorías de la identidad. Buenos Aires: Siglo XXI Editores, 2011.

HEVILLA, C. Configuración de la frontera centro-oeste en el proceso de constitución del Estado argentino (1850-1902). Barcelona: Tesis Doctoral, Universidad de Barcelona, 2002.

INVERNIZZI, L. La representación de la tierra de Chile en cinco textos de los siglos XVI y XVII. Revista Chilena de Literatura, $1984, N^{\circ} 23$, p. 5-37.

LOIS, C. La invención del desierto chaqueño. Una aproximación simbólica de los territorios del Chaco en los tiempos de formación y consolidación del Estado nación argentino. Scripta Nova Revista Electrónica de Geografía y Ciencias Sociales, 1999, № 38. Disponible en internet: http:/www.gh.ub.es/geocrit/sn-38.htm

MATOSSIAN, B. Expansión urbana y migración. El caso de los migrantes chilenos en San Carlos de Bariloche como actores destacados en la conformación de barrios populares. Scripta Nova. Revista Electrónica de Geografía y Ciencias Sociales, 2010, № 331, Vol. XIV. Disponible en internet: http://www. ub.edu/geocrit/sn/sn-331/sn-331-76.htm

MEGE, P. La fuerza del símbolo. Revista Universitaria, 1994, № 45. 
NAVARRO FLORIA, P. Un país sin indios. La imagen de la Pampa y la Patagonia en la geografía del naciente Estado argentino. Scripta Nova. Revista de Geografía y Ciencias Sociales, 1999, N51.

NAVARRO FLORIA, P. (compilador). Patagonia. Ciencia y conquista. La mirada de la primera comunidad científica argentina. Neuquén: Centro de Estudios Patagónicos. Facultad de Ciencias de la Educación. Universidad Nacional del Comahue, 2004.

NAVARRO FLORIA, P. Paisajes del progreso. La Norpatagonia en el discurso científico y político argentino de fines del siglo XIX y principios del XX". Scripta Nova, Revista Electrónica de Geografía y Ciencias Sociales, 2006, No 218, Vol. X. Disponible en Internet: http://www.ub.edu/geocrit/sn/sn218-76.htm

NAVARRO FLORIA, P. (coordinador). Paisajes del progreso. La re-significación de la Patagonia Norte, 1880-1916. Neuquén: Centro de Estudios Patagónicos. Universidad Nacional de Comahue, 2007.

NAVARRO FLORIA, P. y DEL RÍO, W. (compilador). Cultura y Espacio. AraucaníaNorpatagonia. Río Negro: Universidad de Río Negro, 2011.

NOGUE, J. y RUFI, J. Geopolítica, identidad y globalización. Barcelona: Ariel, 2001.

NúÑEZ, A. La Formación y consolidación de la representación moderna del territorio en Chile: 1700-1900. Santiago de Chile: Tesis para optar al grado de Doctor en Historia, Pontificia Universidad Católica de Chile, 2009.

NúÑEZ, A. Discursos territoriales fuertes y débiles: ¿tensión o coexistencia? Chile, Siglos XIX-XX. En: NAVARRO FLORIA, P. y DEL RÍO, W. (compiladores). Cultura y Espacio. Araucanía-Norpatagonia. Río Negro: Universidad de Río Negro, 2011, p. 28-44.

NÚÑEZ, A. El país de las cuencas: Fronteras en movimiento e imaginarios territoriales en la construcción de la nación. Chile, siglos XVIII-XIX. In: XII Coloquio Internacional de Geocrítica, Bogotá, mayo 2012. Disponible en internet: http://www.ub.edu/geocrit/coloquio2012/actas/02-A-Nunez.pdf

ORTIZ, R. Otro territorio. Ensayos sobre el mundo contemporáneo. Quilmes: Universidad Nacional de Quilmes Ediciones, 2002.

POLICASTRO, C. Paraje El Manso: instaurando límites y fronteras al territorio. En: VALVERDE, S.; MARAGLIANO, G.; IMPEMBA, M. y TRENTINI, F. (coordinadores). Procesos históricos, transformaciones sociales y construcciones de fronteras. Buenos Aires: Universidad de Buenos Aires, 2011, p. 223-252.

RISOPATRÓN, L. La línea de frontera con la República Argentina entre las latitudes $35^{\circ}$ y $46^{\circ}$ S. Santiago de Chile: Imprenta Universitaria, 1907.

SÁNCHEZ, E. J. Poder y Espacio. Scripta Nova, Revista Electrónica de Geografía y Ciencias Sociales, 1979, N²3.

SASSEN, S. ¿Perdiendo el control? La SOberanía en la era de la globalización. Barcelona: Ediciones Bellatera, 2001.

TÉlleZ, E. Los Pehuenches Primitivos. Santiago de Chile: Tesis de Magíster, Universidad de Chile, 1990.

TOZZINI, A. Del Límite Natural a la frontera Social. Tierras, Linajes y Memoria en Lago Puelo. Buenos Aires: Tesis de Licenciatura, Universidad de Buenos Aires, 2004.

TORRES, S. La inmigración chilena en la Patagonia Austral en la primera mitad del siglo XX y su inserción en los centros urbanos de Comodoro Rivadavia, Río Gallegos y Ushuaia". En: BANDIERI, S. (coordinadora). Cruzando la cordillera. La frontera argentinochilena como espacio social. Neuquén: Universidad Nacional del Comahue, 2005, p. 421-458.

TREBBI DEL TREVIGIANO, R. Desarrollo y tipología de los conjuntos rurales en la zona central de Chile siglos XVI-XIX. Santiago de Chile: Ediciones Nueva Universidad, 1980.

TUAN, Y. Topofilia: un estudio de las percepciones, actitudes y valores sobre el entorno. España: Melusina, 2007. 
UGARTE, R. Los Pehuenches y su espacio. Santiago de Chile: Tesis de Licenciatura, Pontificia Universidad Católica de Chile, 1996.

VALVERDE, S.; MARAGLIANO, G.; IMPEMBA, M. y TRENTINI, F. (coordinadores). Procesos históricos, transformaciones sociales y construcciones de fronteras. Buenos Aires: Universidad de Buenos Aires, 2011.

VEGA, A. Descripción geográfica e identidad territorial: representaciones hispanas de la cordillera de los Andes del Reino de Chile en el siglo XVI. Santiago de Chile: Tesis Doctoral, Pontificia Universidad Católica de Chile, 2005.

XICARTS, D.; CARACOTCHE, S. y CABRERA, S. El poblamiento del valle del Manso a principios del siglo XX: diálogos entre
Antropología e Historia. En: VALVERDE, S.; MARAGLIANO, G.; IMPEMBA, M. y TRENTINI, F. (coordinadores). Procesos históricos, transformaciones sociales y construcciones de fronteras. Buenos Aires: Universidad de Buenos Aires, 2011, p. 253-274.

ZUSMAN, P. y MINVIELLE, S. Sociedades geográficas y delimitación del territorio en la construcción el Estado-Nación argentino. Trabajo presentado en $V$ Encuentro de Geógrafos de América Latina, La Habana, Cuba. 1995. Disponible en internet: http://www.educar.ar.

ZUSMAN, P. Representaciones, imaginarios y conceptos en torno a la producción material de fronteras. Biblio 3W. Revista Bibliográfica de Geográfica y Ciencias Sociales, 1999, № 149. Disponible en internet: http:/www.ub.es/geocrit/b3w-149.htm 